\title{
ROUSSEAU E O SENTIMENTO DE EXISTÊNCIA COMO RECURSO AUTOBIOGRÁFICO E AUTOFORMATIVO
}

\author{
Marlene de Souza Dozol ${ }^{1}$ \\ Lia Presgrave Reis ${ }^{2}$
}

\begin{abstract}
Resumo:
A obra rousseauniana encarna o sentimento de existência quando a solidão aparece da forma expressiva observada n'Os Devaneios do caminhante solitário, nas Confissões e nos Diálogos: Rousseau, juiz de Jean-Jacques, obras autobiográficas do filósofo. Diante da impossibilidade histórica de recuperar a unidade perdida na máscara das relações sociais e de alcançar a felicidade que a vida mundana não the havia proporcionado, Jean-Jacques volta-se para a interioridade, escolhendo o isolamento como condição existencial. Na impossibilidade de transformar o mundo exterior, recorre à reforma interior visando à redenção individual. Nosso interesse na obra de Rousseau se concentra no deslocamento desta, começada como uma filosofia da história universal em direção a uma literatura que imprime uma "experiência existencial" (STAROBINSKI, 2011, p. 52). Conforme Burgelin (1978), Starobinski (2011) e Prado Jr. (2008), os quais consideram Rousseau um precursor das filosofias da existência, intencionamos destacar essa abordagem para a existência na obra literária e autobiográfica rousseauniana, colocando-a como problema filosófico para daí extrair um problema filosófico-educacional concernente à autoformação. Pretendemos enfatizar a visão de um autor-personagem examinador de sua experiência vital e que, ao identificar situações cruciais e banais, transforma-as em matéria-prima para seu pensamento, para o filosofar e para a confecção de um si mesmo. Concluímos que a solidão para Rousseau é também um recurso para a fabricação do "eu" tanto na vida quanto em sua obra. Nos textos autobiográficos, a solidão é um meio para o indivíduo empreender o exame estético de consciência intencionando melhor compreender a si mesmo. Concluímos igualmente que o sentimento de existência equivale à consciência de existir, a qual, abrangendo razão e sentimento, significa intenção e atitude que encontram na linguagem sua possibilidade mais recorrente de expressão. Desse modo, o sentimento de existir instaura nossa existência no sentido de que dele emerge a consciência de si cuja intensificação, em Rousseau, necessita da solidão para exaltar o sentimento de existência. $\mathrm{O}$ conceito de existência em Rousseau somente adquire a devida relevância se entendido na concretude de um sentimento de existir no contexto da condição humana de um estar no mundo que vivencia e indaga a própria existência.
\end{abstract}

Palavras-chave: Sentimento de existência. Solidão. Autoformação. Autobiografia. Jean-Jacques Rousseau.

\section{ROUSSEAU AND THE FEELING OF EXISTENCE AS AN AUTOBIOGRAPHIC AND SELF-FORMATIVE RESOURCE}

\begin{abstract}
:
The Rousseaunian work embodies the feeling of existence when solitude appears in the expressive form observed in the following autobiographical works of the philosopher: Reveries of a Solitary Walker, The Confessions and Dialogues: Rousseau, Judge of Jean-Jacques. Faced with the historical impossibility of recovering the lost unity in the mask of social relations and of achieving the happiness that mundane life had not afforded him, JeanJacques turns to interiority by choosing isolation as an existential condition. Unable to transform the outer world,

1 Professora Titular da Universidade Federal de Santa Catarina. Atua na linha de pesquisa Filosofia da Educação ligada ao Programa de Pós-Graduação em Educação (PPGE/UFSC). É líder do Grupo de Pesquisa GRAFIA - Grupo de Estudos em Filosofia da Educação e Arte/CNPQ. E-mail: lena.dozol@uol.com.br.

2 Doutoranda no Programa de Pós-Graduação em Educação da Universidade Federal de Santa Catarina (PPGE/UFSC). É membra do Grupo de Pesquisa GRAFIA - Grupo de Estudos em Filosofia da Educação e Arte/CNPQ. E-mail: liapresgrave@gmail.com.
\end{abstract}


his resource is inner reform aiming for individual redemption. Our interest in Rousseau's work focuses on its dislocation begun as a philosophy of universal history towards a literature that imprints an "existential experience" (STAROBINSKI, 2011, p. 52). According to Burgelin (1978), Starobinski (2011) and Prado Jr. (2008) which consider Rousseau a precursor of the philosophies of existence, we intend to highlight this approach to existence in the Rousseaunian literary and autobiographical work, placing it as a philosophical problem to extract from it a philosophical educational problem that concerns self-formation. We intend to emphasize the view of an authorcharacter examining his vital experience and that, by identifying crucial and trivial situations, transforms them into the raw material for his thinking, philosophizing, and making of himself. We conclude that solitude for Rousseau is also a resource for the making of himself in both life and work. In autobiographical texts, solitude is a means for the individual to undertake the aesthetic examination of consciousness in order to better understand himself. We also conclude that the feeling of existence is equivalent to the awareness of existence, which, encompassing reason and feeling, means intention and attitude that find in language their most recurrent possibility of expression. Thus, in Rousseau's work the feeling of existence establishes our existence in the sense that from it emerges selfconsciousness whose intensification needs solitude to exalt the feeling of existence. Rousseau's concept of existence is relevant only if understood in the concreteness of a feeling of existing in the context of the human condition of being in the world experiencing and inquiring into existence itself.

Keywords: Feeling of existence. Solitude. Self-formation. Autobiography. Jean-Jacques Rousseau.

\section{A existência como problema filosófico na obra rousseauniana}

A obra rousseauniana encarna o que chamamos aqui de sentimento de existência quando a solidão — simultaneamente problema e solução na obra de Jean Jacques Rousseau aparece da forma expressiva observada n'Os Devaneios do caminhante solitário (1782), nas Confissões (1813) e nos Diálogos: Rousseau, juiz de Jean-Jacques ${ }^{3}$ (1782), obras autobiográficas do filósofo. Diante da impossibilidade histórica de recuperar a unidade perdida na máscara das relações sociais e, consequentemente, de alcançar a felicidade que a vida mundana não lhe havia proporcionado, Jean-Jacques volta-se para sua interioridade ao escolher o isolamento como condição existencial. Não sendo possível transformar o mundo exterior, seu recurso é a reforma interior (moral), visando à redenção individual, o que resulta numa filosofia da existência deveras particular. Nos Diálogos, Rousseau (1959c, p. 952; trad. bras. 2012, p. 226), referindo-se a si mesmo na terceira pessoa, explica como a perseguição empreendida contra ele e suas obras o conduziu à solidão cujo resultado termina por ser parcialmente benéfico, visto que o asilo na interioridade resguardaria sua natureza intocável, uma porção inacessível de si mesmo que garantiria a integridade do filósofo: "Mas, fazendo-lhe todo o mal que puderam, forçaram-no a procurar refúgio em asilos nos quais não está ao alcance deles adentrar".

3 Em tradução livre. A obra não apresenta edição em português. As traduções dos excertos dos Diálogos presentes neste artigo foram realizadas por nós.

\begin{tabular}{|c|c|c|c|c|}
\hline Govista Dialectus & Ano 8 & n. 15 & Agosto - Dezembro 2019 & p. $122-142$ \\
\hline
\end{tabular}


Ainda que não possamos afirmar que a filosofia da existência em Rousseau inicia com a escritura dos textos literários e autobiográficos — pois a ideia de existência, pela própria abrangência do conceito, paira sobre toda a sua filosofia além de fornecer nexos entre a biografia e a obra do filósofo quando possível - , nosso interesse na obra de Rousseau se concentra no próprio deslocamento desta, obra começada como uma filosofia da história universal em direção a uma literatura que imprime uma "experiência existencial" (STAROBINSKI, 2011, p. 52).

Acompanhando as teses de Burgelin (1978), Starobinski (2011) e Prado Jr. (2008), as quais consideram Rousseau um precursor ${ }^{4}$ do que posteriormente encontraria ambiência para o surgimento das filosofias da existência, intencionamos destacar essa abordagem para a existência na obra literária e autobiográfica rousseauniana, colocando-a como problema filosófico para daí extrair um problema filosófico-educacional concernente à autoformação. Em outras palavras, pretendemos enfatizar a visão de um autor-personagem examinador de sua experiência vital e que, ao identificar situações cruciais e banais, transforma-as em matériaprima para seu pensamento, para o filosofar (transformador e transformado por esse existir) e para a própria confecção de um si mesmo ao ritmo de suas próprias inquietações, anseios e possibilidades expressivas.

Mas temos, nesse caso, uma filosofia da existência que considera uma vida em particular em sua conexão com o universal. A propósito, Prado Jr. (2008, p. 52) lança uma interrogação pertinente que de algum modo mostra a reciprocidade da relação singularuniversal que abriga o pensamento em torno da filosofia da existência rousseauniana: “[...] a existência é o objeto da reflexão de Rousseau ou a reflexão de Rousseau é a expressão de sua existência?". Seriam ambas inseparáveis na obra do pensador em exame? Soma-se a isso um elemento complicador: a linguagem utilizada para exprimir essa existência, ainda que precise estar respaldada na realidade por ser autobiográfica, por ser igualmente literária é também obra do artifício, da ficção, da construção de um si mesmo. Contudo, no caso de aceitarmos tais hipóteses, por que em Rousseau a experiência existencial é tão importante a ponto de ser digna de análise e expressão?

Inicialmente porque vida e obra são indissociáveis na obra do filósofo genebrino apesar da presença do artifício inerente à linguagem literária. Em segundo lugar, é preciso pensar no ineditismo e na originalidade representados pela figura humana de Rousseau à época,

4 Pierre Burgelin (1978) é mais enfático na constatação de Rousseau como um filósofo da existência de tal modo que a obra referenciada é intitulada La philosophie de l'existence de Jean-Jacques Rousseau.

\begin{tabular}{|c|c|c|c|c|}
\hline Revita Alatectus & Ano 8 & n. 15 & Agosto - Dezembro 2019 & p. $122-142$ \\
\hline
\end{tabular}


rechaçada em certa medida por suas extravagâncias e exageros inúmeros. De fato, trata-se de um filósofo que, se não inaugura uma tradição autobiográfica, radicaliza a exposição da vida íntima e dos sentimentos do seu autor-personagem, e que "[...] traria para [...] [o] âmbito da filosofia e da literatura uma noção [...] intensificada de interioridade" (ROSSATTI, 2014, p. 112). Tais atitudes poderiam ser consideradas como iniciadoras do que posteriormente se consolidaria como romantismo numa de suas tantas facetas. Além disso, uma existência específica adquire relevância pelo modo singular como ela é vivida e, no caso de Rousseau, como essa "experiência subjetiva" pôde influenciar a história das ideias e a literatura ocidental, expondo novas possibilidades de formas de vida, de arte e de pensamento cuja singularidade "é reveladora de uma verdade universal" (BURGELIN, 1978, p. 131) ${ }^{5}$. Mas é Starobinski quem melhor resume a importância da existência de Rousseau:

[...] esse recolhimento na singularidade, longe de enfraquecer a influência histórica de Rousseau, ao contrário, reforçou-a. Se Rousseau mudou a história (e não apenas a literatura), essa ação não se operou apenas sob o efeito de suas teorias políticas e de suas concepções sobre a história: resulta, numa porção talvez mais considerável, do mito que se elaborou em torno de sua existência excepcional. Ele era sem dúvida sincero ao afastar-se do mundo, ao desejar tornar-se nulo para os outros: mas sua maneira de se distanciar do mundo transformou o mundo (STAROBINSKI, 2011, p. 66).

Ao discutir o problema da existência na coletânea de ensaios $A$ retórica de Rousseau, Bento Prado Jr. (2008, p. 43) afirma ser Jean-Jacques o pensador profético que antecipa os temas existência e discurso, sociabilidade e linguagem, natureza e cultura, notáveis na Modernidade. Além disso, ele aponta o lugar estratégico ocupado pela figura de Rousseau no pensamento moderno e na história ocidental, provavelmente pelo caráter visionário do seu pensamento que abriu caminhos em diversas áreas do conhecimento ${ }^{6}$. No subcapítulo "A existência” da referida coletânea, Prado Jr. aproxima o pensamento de Rousseau do pensamento contemporâneo através do nexo de ambos com a filosofia da existência. Sem a intenção de considerá-lo contemporâneo, sua atitude é solidária à herança deixada pelo filósofo genebrino no sentido de posicionar sua filosofia nas raízes do que posteriormente seria denominado

5 As traduções dos excertos de La philosophie de l'existence de Jean-Jacques Rousseau presentes neste artigo foram realizadas por nós.

6 Entre elas podemos citar a sociologia, com a elaboração da hipótese sobre a gênese da desigualdade e do mal presente no Discurso sobre a origem e os fundamentos da desigualdade entre os homens; a literatura francesa, inaugurando a tônica romântica tanto da afirmação radical do "eu" no trabalho autobiográfico das Confissões quanto do modelo de romance surgido com Júlia ou a Nova Heloísa, que muito inspiraria o movimento romântico representado nas figuras de Schiller, Goethe, entre outros ilustres leitores românticos de Rousseau e a filosofia da existência como vimos.

\begin{tabular}{|l|c|c|c|c|}
\hline Q Ponista Dialectus & Ano 8 & n. 15 & Agosto-Dezembro 2019 & p. $122-142$ \\
\hline
\end{tabular}


pensamento contemporâneo. Em relação a isso, Rossatti menciona o comentário de Charles Taylor que é de certo modo semelhante ao de Prado Jr.:

\begin{abstract}
Rousseau está na origem de grande parte da cultura contemporânea, das filosofias de autoexploração, assim como dos credos que fazem da liberdade autodeterminante a chave para a virtude. Ele é o ponto de partida de uma transformação da cultura moderna no sentido de uma interioridade mais profunda e de uma autonomia radical (TAYLOR, 1997, p. 464).
\end{abstract}

\title{
Rousseau e o conhecimento de si
}

É possível conhecer o "eu” ou, em meio a tamanho mal-entendido, incompreensão e ruído provenientes da conspiração da qual foi alvo, o conhecimento de si seria mesmo uma quimera para Rousseau? O conhecimento de si dependeria, então, de uma vinculação com a sociedade, com o exterior? É possível o conhecimento ou a "posse" de si, recobrar a integridade do "eu" através da escrita?

Para Starobinski (2011, p. 246), o conhecimento de si não é um problema para Jean-Jacques, pois aquele é intuitivo, e é efetivamente na solidão que o filósofo poderia exacerbar o sentimento de sua existência: “Quem sou eu? A resposta a essa pergunta é instantânea. 'Sinto o meu coração.' [...] Para Jean-Jacques, o conhecimento de si não é um problema, é um dado: 'Passando minha vida comigo, devo conhecer-me"'. No entanto, Carla Damião e Franklin Leopoldo Silva (2006) mostram que a solidão de Rousseau se torna destrutiva porque, ao perder a capacidade de comunicação com seus contemporâneos, seu "eu" se desintegra, o que apontaria o germe para uma posterior crise da narrativa devido à "fragilidade do conceito de sujeito" (DAMIÃO, 2006, p. 42), crise iniciada no século XVIII cujo ápice foi atingido nos séculos XIX e XX ao manifestar a dificuldade do indivíduo de compreender a si mesmo, "[d]a capacidade de autoexame, já que desfia a trama de uma possível organicidade entre o indivíduo e seu contexto" (SILVA, 2006, p. 13). Silva (2006, p. 12) indica que, na Modernidade na qual Rousseau despontava, começaria "a dissolução do ideal clássico de harmonia entre o sujeito e o mundo" devido à "perda da coesão interna que propiciou a transformação da intimidade em estranhamento”. Franklin Leopoldo de fato aponta Rousseau como o precursor desse problema na Modernidade. O curioso é que, se por um lado, através da autobiografia, Rousseau aprofunda a noção de intimidade ao revelar-se tão intensa e radicalmente, por outro, a partir da emergência do "eu" num relato tão íntimo, o vínculo do indivíduo com o mundo passa a se desintegrar, o que parecia negar as ambições de

\begin{tabular}{|l|l|l|l|l|}
\hline Gonista Dialectus & Ano 8 & n. 15 & Agosto-Dezembro 2019 & p. $122-142$ \\
\hline
\end{tabular}


comunicação do filósofo com os demais. E como ninguém é uma ilha, tal desintegração e desarmonia não ocorreriam sem prejuízo para Rousseau.

Ao considerar que a sociedade e os costumes o afastavam do seu "eu" verdadeiro e que a transparência buscada por ele seria impossível de ser encontrada em meio ao convívio, Rousseau constata que o mergulho em si mesmo precisaria ser realizado num estado de solidão. Todavia, quando se opõe definitivamente à sociedade, encara como um mal quase tudo o que é exterior a ela:

O "outro" torna-se o inimigo; em Rousseau, a sociedade e seus costumes o afastaram em direção contrária ao impulso mais profundo do seu "eu" verdadeiro. Depositar no outro as razões do desconhecimento de si faz com que o verdadeiro "eu" permaneça oculto e não questionado (DAMIÃO, 2006, p. 39).

A reflexão de Damião problematiza a atitude rousseauniana de oposição à sociedade, como se, ao responsabilizar o outro pelo desconhecimento de si - o qual, neste caso, relacionaríamos ao isolamento proveniente da sua dificuldade de comunicação com os outros, fonte de angústia e desordem para o filósofo — o "eu" rousseauniano permanecesse oculto e não questionado, pois a fonte dos males seria sempre exterior a ele. Assim como a solidão que propicia a escrita serviria como meio para o autor afirmar sua existência de modo radical, precisamos admitir que sua obra autobiográfica enseja um esforço de compreensão do "eu" ou que o próprio "fazer" autobiográfico já implicaria essa pretensão. Apesar disso, a problematização empreendida por Damião e Silva (2006) significa que o conhecimento de si passa necessariamente por uma relação com o outro. Ademais, conforme a autora aponta, o conhecimento de si em Rousseau, não se completaria porque

a afirmação de substancialidade do "eu" cartesiano alimentava-se do pressuposto de que a reflexão, possuindo um caráter universalmente objetivante, paralelo à certeza, poderia objetivar o "eu" levando a um conhecimento absolutamente claro de si mesmo. Mas, quando somos forçados a admitir a temporalidade e a contingência como condições da experiência subjetiva, vemos que a reflexão sobre si se desdobra em sombra e opacidade (DAMIÃO, 2006, p. 14).

Dessa maneira, a crise do conhecimento de si corresponde, portanto, a uma crise do pensamento cartesiano cuja primazia será destronada para a compreensão do "eu" a partir do século XVIII.

Rousseau cria ser necessária a solidão para viver e compor sua obra. E assim ele mergulha em si mesmo, se volta para dentro. Em As fontes do self: a construção da identidade

\begin{tabular}{|c|c|c|c|c|}
\hline Rovista Dialectus & Ano 8 & n. 15 & Agosto - Dezembro 2019 & p. $122-142$ \\
\hline
\end{tabular}


moderna, Charles Taylor (1997, p. 464) relaciona este voltar-se para dentro à definição rousseauniana de "consciência como um sentimento interior", disposição natural, voz interior que define o bem para o indivíduo e na qual o sujeito deve buscar sua unidade. No texto sobre a "Profissão de fé do vigário saboiano" presente no Emílio, Rousseau (1969a, p. 598; trad. bras. 2004, p. 409) exprime seu conceito de consciência:

Existe, pois, no fundo das almas um princípio inato de justiça e de virtude a partir do qual, apesar de nossas próprias máximas, julgamos nossas ações e as de outrem como boas ou más, e é a esse princípio que dou o nome de consciência.

Como, de acordo com Rousseau, a sociedade representa o mal e a corrupção, todo o conhecimento de si passa a se basear unicamente numa noção de natureza metafísica - noção com cuja conformidade depende a felicidade do indivíduo - manifesta na consciência. Localizada no interior do "eu", é na consciência onde se deveria buscar a integridade, a unidade do sujeito: "o bem é descoberto em parte através de um voltar-se para dentro" (TAYLOR, 1997, p. 463) em vez de buscar um critério objetivo de conhecimento de si e do mundo como preconiza o pensamento cartesiano. Assim, a "afirmação da subjetividade", do "eu", dessa existência implica um "conhecimento de si baseado no sentimento" (DAMIÃO, 2006, p. 26).

Contudo, nos parece que o genebrino encarou muito obcecadamente a tarefa de mergulhar em si próprio a ponto de esse mergulho no interior tornar-se um delírio e Starobinski (2011, p. 246) declarar que "à medida que Jean-Jacques mergulhar em seu delírio e perder seus vínculos com os homens, o conhecimento de si lhe parecerá mais complexo e mais difícil”. Era como se tudo fosse sobre ele e, sem outro parâmetro que não fosse o si mesmo, ele perdesse a imagem do contraponto ao seu pensamento que seria fornecido pelo exterior como afirma Damião (2006, p. 76): “Sem a revelação de si pelas condições do mundo ao redor, há incerteza e desconfiança de que o conhecimento de si mesmo seja possível". Diante disso, como garantir que a confiança de Rousseau em seu juízo não era uma teimosia, uma obsessão ou uma loucura? No plano retórico e teórico, a saída encontrada por ele para garantir a sinceridade da sua obra ocorre a partir da noção de força da linguagem ${ }^{7}$, porém no plano da personalidade permanecem o delírio, a obsessão com o próprio eu. Parece-nos que o exercício do conhecimento de si em Rousseau restou inconcluso, muito embora ele certamente seja a tarefa

7 Para maiores esclarecimentos a respeito desta expressão em Rousseau, cf. em PRADO JR. (2008) o item II da primeira parte intitulado "A força da linguagem”.

\begin{tabular}{|l|l|l|l|l|}
\hline Qenista Dialectus & Ano 8 & n. 15 & Agosto-Dezembro 2019 & p. $122-142$ \\
\hline
\end{tabular}


de uma vida porque aquele só é valido, conforme adverte Starobinski (2011, p. 248-249), caso haja "a tradução da consciência de si em um reconhecimento de fora":

o que os escritos autobiográficos vão colocar em discussão não será o conhecimento de si propriamente dito, mas o reconhecimento de Jean-Jacques pelos outros. [...] Por que é tão difícil fazer concordar o que se é para si e o que se é para os outros?

\section{O "eu", a consciência, o sentimento de existência na escrita de si}

Rossatti (2014, p. 98, grifo do autor) afirmará que “[ ...] a questão do surgimento da autoconsciência na Modernidade [...] necessariamente também passa por Rousseau". Marcel Raymond em Jean-Jacques Rousseau: la quête de soi et la rêverie relata o interesse que o conhecimento de si passa a atrair desde o Medievo e a intensificação que adquire na Modernidade:

Desde o fim da Idade Média, desde a época na qual se começou a se olhar nos belos espelhos polidos dos venezianos, desde Petrarca, desde Montaigne, mais precisamente desde Rousseau - através do romantismo, do simbolismo, do existencialismo, de Baudelaire, Amiel, Kierkegaard, Nietzsche, Mallarmé, Valéry, Kafka - uma parte essencial da aventura do homem moderno é a da consciência de si como obsessão - e também como paixão ${ }^{8}$ (RAYMOND, 1962, p. 193).

Pensar a consciência de si na obra literária de Rousseau significa refletir acerca de uma filosofia que se nutre da solidão para concentrar e exacerbar o si mesmo, alçando-o a um parâmetro para pensar e conduzir uma existência solitária enquanto condição existencial na sua relação com o restante, sejam pessoas ou natureza em forma de plantas e flores (tão ao gosto do herborizador Rousseau $)^{9}$. Dito de outro modo, Pierre Burgelin (1978, p. 126) declara que a "consciência da existência como valor se transforma no princípio de nossa vida moral".

8 Na obra rousseauniana, o conceito de consciência adquire o estatuto de sentimento inato, o que representa uma novidade para o leitor contemporâneo (PRESGRAVE, 2015). Como todo sentimento inato para Rousseau, a consciência representa uma das formas de manifestação de uma natureza metafísica, e igualmente uma espécie de parâmetro ou valor que parte do interior do indivíduo e o auxilia na distinção do que é obra da natureza (sentimento inato, natural) e do que é atribuição do artifício. Ao invés de considerar a consciência como voz da razão, o filósofo a caracteriza como voz interior ou voz da natureza. A esse respeito, Rousseau é categórico ao afirmar [...]: "Vezes demais a razão nos engana [...], mas a consciência nunca engana. Ela é o verdadeiro guia do homem; [...] quem a segue obedece à natureza e não tem medo de se perder" (ROUSSEAU, 1969a, p. 594595; trad. bras. 2004, p. 405). Desse modo, Rousseau "elege um lugar privilegiado para a natureza na conduta do indivíduo no sentido de esse ideal de natureza auxiliá-lo na conexão com a porção mais genuína do seu ser e no estabelecimento de relações mais autênticas com os outros" (PRESGRAVE, 2015, p. 69).

9 Nos Diálogos, Rousseau (1959c, p. 794; trad. bras. 2012, p. 103) associa a contemplação da natureza a uma espécie de compensação para a solidão: "É evidente que seu coração sempre teve uma grande atração pela contemplação da natureza. Ele encontrou nela um complemento para as afeições de que precisava. Mas ele teria desistido do complemento para a coisa em si se tivesse escolha. Ele não se limitou a conversar com

\begin{tabular}{|c|c|c|c|c|}
\hline Q Oonista & Ano 8 & n. 15 & Agosto-Dezembro 2019 & p. $122-142$ \\
\hline
\end{tabular}


Ora, se concordarmos que "existir é uma arte", um pensador dedicado a refletir sobre a existência não é exatamente um homem de ciência e sim um artista (ROSSATTI, 2014, p. 115). Além disso, a linguagem adequada para exprimir o sentimento de existência é mais próxima da literatura do que de um repertório conceitual fundamentado na ordem da razão. Sendo assim, poderíamos pensar que o sentimento de existência, que tem a consciência da existência como valor, em Rousseau, indicaria uma criação de si forjada tanto por meio da autobiografia quanto das vivências do filósofo artista.

A ênfase numa pesquisa sobre a filosofia da existência de um autor embasada em seus escritos literários e autobiográficos se fortalece com a tese de Burgelin (1978, p. 118) segundo a qual a filosofia de Rousseau "é, sobretudo, doutrina da consciência e da manifestação de si" muito embora saibamos que a linguagem jamais conseguirá expressar tudo que se pretende dizer ou traduzir um sentimento, o que nos leva a concluir que esse "eu" é obstáculo até quando o seu desejo é o de transparência. Burgelin (1978, p. 144) continua a detalhar a autoconsciência, relacionando-a ao sentimento de existência: "A concentração da consciência produz intensidade, exalta o sentimento de si em detrimento da sensação e da reflexão que nos dispersam”. A conotação maléfica atribuída por Rousseau à ação de refletir que não se confunde com a ideia de consciência nele encontrada, ou seja, a de um princípio inato ditado pelo sentimento - aparece devido à sua crença de que a reflexão como artefato exclusivo da abstração é fonte de engano ou sofrimento porque lança o indivíduo para fora de si mesmo, como se isso de algum modo dispersasse a concentração do sentimento de existência. No Discurso sobre a origem e os fundamentos da desigualdade entre os homens, Rousseau (1964, p. 138; trad. bras. 1973, p. 247, grifo nosso) é contundente:

[...] a maioria de nossos males é obra nossa e [...] teríamos evitado quase todos se tivéssemos conservado a maneira simples, uniforme e solitária de viver prescrita pela natureza. Se ela nos destinou a sermos sãos, ouso quase assegurar que o estado de reflexão é um estado contrário à natureza e que o homem que medita é um animal depravado.

Ademais, a atitude da qual aflora o sentimento de existência em algumas das obras mencionadas é mais a da contemplação do esteta vivendo dentro do instante e desfrutando dos

plantas até que seus esforços para conversar com seres humanos se mostrassem inúteis". Mais adiante, Rousseau (1959c, p. 833; trad. bras. 2012, p. 134) reafirma o nexo entre o gosto pelas atividades botânicas e sua condição solitária: “[...] o encanto de estudar a natureza é algo para todas as almas sensíveis e um ótimo negócio para uma pessoa solitária".

\begin{tabular}{|c|c|c|c|c|}
\hline Rovista Dialectus & Ano 8 & n. 15 & Agosto - Dezembro 2019 & p. $122-142$ \\
\hline
\end{tabular}


prazeres descortinados pelo momento do que a do filósofo refletindo muito racionalmente sobre sua condição existencial:

A vida contemplativa desencoraja a ação. [...] A reflexão e a previsão [...] mal se aproximam de uma alma intoxicada pelos encantos da contemplação. Todas as tarefas cansativas da vida ativa tornam-se insuportáveis e parecem supérfluas. E por que se dar ao trabalho de ter uma esperança remota de [...] um sucesso tão incerto enquanto alguém pode [...] em um devaneio delicioso desfrutar [...] de toda a felicidade de que se sente capaz e necessitado? (ROUSSEAU, 1959c, p. 822; trad. bras. 2012, p. 125).

Ainda nos Diálogos, Jean-Jacques é categórico ao reiterar o seu aborrecimento relacionado à reflexão:

Pensar é um trabalho muito doloroso para mim, que me cansa, atormenta e desagrada.
Trabalhar com as mãos e descansar a cabeça me refresca e me diverte. Se às vezes
gosto de pensar, é livremente e sem restrições, deixando minhas ideias fluírem à
vontade sem submetê-las a nada (ROUSSEAU, 1959c, p. 839; trad. bras. 2012, p.
139).

Não é demais repetir que, em Rousseau, o conceito de consciência equivale a um sentimento inato. Todavia, ele não corresponde apenas a um sentimento. Ao longo de sua explanação sobre o sentimento de existência, observaremos a diferenciação realizada por Burgelin entre a estrita reflexão e a consciência de si que exalta o sentimento de existência. Este último é um pensar e uma atitude diversos da "pura" reflexão porque também é composto de sentimento, o que instauraria uma relação de reciprocidade entre pensamento e sentimento, portanto não excludentes na obra de Rousseau.

Rousseau expressa o sentimento de existência de forma um pouco exagerada ao longo de sua obra talvez para realçar a ideia de que a existência é, antes de tudo, um sentimento ou que deve haver a primazia do sentimento para fazer surgir o sentimento de existência. Em Emílio ele diz na "Profissão de fé do vigário saboiano": "Para nós, existir é sentir; nossa sensibilidade é incontestavelmente anterior à nossa inteligência, e tivemos sentimentos antes de ter ideias" (ROUSSEAU, 1969a, p. 600; trad. bras. 2004, p. 410-411). A respeito do primado do sentimento em relação ao pensamento, o romantismo de Rousseau desvelado na "Quinta Caminhada" dos Devaneios nos fornece exemplos do que seria essa compreensão e criação de si apoiadas nas sensações e no sentimento ao expor a natureza como conteúdo da consciência de um "eu" que desliza nas águas de um lago, aquele, no caso, sendo o próprio personagem Rousseau:

\begin{tabular}{|c|c|c|c|c|}
\hline Genista Dialectus & Ano 8 & n. 15 & Agosto-Dezembro 2019 & p. $122-142$ \\
\hline
\end{tabular}


O fluxo e refluxo dessa água, seu ruído contínuo, mas crescente por intervalos, atingindo sem repouso meus ouvidos e meus olhos, supriam os movimentos internos que o devaneio extinguia em mim e bastavam para me fazer sentir com prazer minha existência sem ter o trabalho de pensar. De tempos em tempos, nascia alguma fraca e curta reflexão sobre a instabilidade das coisas deste mundo do qual a superfície das águas me oferecia a imagem: mas, em breve, essas impressões leves se apagavam na uniformidade do movimento contínuo que me embalava [...] (ROUSSEAU, 1959b, p. 1045; trad. bras. 1995, p. 75).

Nesta última cena dos Devaneios, apesar de virem à mente do personagem breves reflexões existenciais sobre a instabilidade das coisas do mundo, a experiência da fusão romântica do "eu" com a natureza importa mais do que qualquer tipo de reflexão realizada por ele. A indistinção entre fantasia e realidade provocada pelo devaneio, além de promover tal fusão, proporciona uma identificação do "eu" com a totalidade:

Saindo de um longo e doce devaneio, vendo-me rodeado de verdura, de flores, de pássaros e deixando vagar meus olhos ao longe sobre as romanescas margens que rodeavam uma vasta extensão de água clara e cristalina, assimilava às minhas fícções todos esses amáveis objetos e, enfim, voltando pouco a pouco a mim mesmo e ao que me rodeava, não podia marcar o ponto de separação entre ficções e realidades [...] (ROUSSEAU, 1959b, p. 1048; trad. bras. 1995, p. 77).

Totalidade essa que pode igualmente ser denominada natureza:

Nunca medito, nunca sonho mais deliciosamente do que quando me esqueço de mim mesmo. Tenho êxtases, arroubos inexprimíveis a ponto de me fundir [...] no conjunto dos seres, de me identificar com a natureza inteira (ROUSSEAU, 1959b, p. 1065 1066; trad. bras. 1995 , p. 95 ).

No excerto da página 75, transcrito acima, Rousseau declara que a vivência prazerosa de instantes como aquele caracterizam o sentimento de existir. Mas apenas experiências desfrutáveis e apaziguadoras incitariam em nós o sentimento de existência? Nos Devaneios, Rousseau nos mostra como a felicidade simples vivida na plenitude de um eterno presente, a exemplo dos devaneios infantis, pode traduzir o sentimento de existência:

[...] se há um estado em que a alma encontra um apoio bastante sólido para descansar inteiramente e reunir todo o seu ser, sem precisar lembrar o passado nem avançar para o futuro; em que o tempo nada é para ela, em que o presente dura sempre [...], sem nenhum outro sentimento de privação nem de alegria, de prazer nem de dor, de desejo nem de temor, a não ser o de nossa existência e em que esse único sentimento possa preenche-la completamente, enquanto esse estado dura, aquele que o vive pode ser chamado feliz, não de uma felicidade imperfeita, pobre e relativa, como a que se encontra nos prazeres da vida, mas de uma felicidade suficiente, perfeita e plena, que não deixa na alma nenhum vazio que sinta a necessidade de preencher (ROUSSEAU, 1959b, p. 1046; trad. bras. 1995, p. 76, grifo nosso).

\begin{tabular}{|c|c|c|c|c|}
\hline Genista Dialectus & Ano 8 & n. 15 & Agosto-Dezembro 2019 & p. $122-142$ \\
\hline
\end{tabular}


Dessa maneira, Rousseau exprime como o sentimento de existência pode ser profundo também em sua superfície, proporcionando genuína felicidade e o sentimento de harmonia entre o indivíduo e o todo: “[...] enquanto este estado [de felicidade] dura bastamonos a nós mesmos como Deus. O sentimento da existência, despojado de qualquer outro apego é por si mesmo um sentimento precioso de contentamento e de paz" (ROUSSEAU, 1959b, p. 1047; trad. bras. 1995, p. 76).

Entretanto, convém irmos além formulando uma outra pergunta: bastar-nos-ia existir para sentirmos nossa própria existência pelo simples fato de estarmos vivos e disso sabermos ou o sentimento de existência requer algo mais para ser experienciado, a exemplo de uma atitude estética em relação a própria vida como nos mostra o genebrino? $\mathrm{Na}$ "Profissão de fé do vigário saboiano", Rousseau apresenta seus questionamentos acerca da existência: "Terei um sentimento próprio de minha existência, ou só a sinto por minhas sensações?" (ROUSSEAU, 1969a, p. 570-571; trad. bras. 2004, p. 378). Acerca desse comentário, Burgelin (1978, p. 124, grifo nosso) expõe que, embora haja "estreita relação entre o sentimento e a ideia", "a ação de um objeto sobre mim é ideia se me ocupo primeiro do objeto [...]. O sentimento é minha presença vivida como tal em face de um objeto, e ousar-se-ia quase formular: 'Eu sou porque penso mal, [...] porque não penso' ’”. Assim, o comentador nos mostra que o sentimento de existência é peculiar a quem o experimenta porque é uma presença vivida do indivíduo diante de algo e não apenas a ação de um objeto sobre ele. Burgelin segue o raciocínio comparando o conceito de existência de Descartes com o de Rousseau, informando que enquanto no primeiro

o pensamento revela a existência, mas nos fixa no ser, em Rousseau o sentimento de existência nos instala no ser como presença no mundo e de si e mesmo o pensamento é um modo secundário que tende a encobrir o feito original por meio de palavras (BURGELIN, 1978, p. 124).

Para compreender o sentimento de existência, partimos, por conseguinte, do "Penso, logo existo" cartesiano em direção ao "Sinto, logo existo" rousseauniano. Diante disso, podemos admitir que a existência em Rousseau se comparada a Descartes é um fenômeno mais dinâmico do que no caso deste último em cuja filosofia o pensamento determina o ser. A presença no mundo abordada por Burgelin refere-se a uma densidade de presença que sente e pensa a si mesma — não significando somente estar no mundo, "existir" —, o que, para Rousseau, significaria o sentimento de existência. A presença de si, por seu turno, representa a aquisição da consciência de si, a "posse de si", o conhecimento de si, tarefa sempre inacabada

\begin{tabular}{|l|l|l|l|l|}
\hline Govista Dialectus & Ano 8 & n. 15 & Agosto-Dezembro 2019 & p. $122-142$ \\
\hline
\end{tabular}


que o próprio Rousseau (1959b, p. 995; trad. bras. 1995, p. 23) exprimirá nos seus Devaneios: "Mas eu, afastado deles e de tudo, que sou eu mesmo? Eis o que me falta procurar. Infelizmente, essa procura deve ser precedida por um exame da minha situação”. Mais adiante, o genebrino enfatizaria a dificuldade deste aprendizado: “[...] vim com a opinião já bem confirmada de que o conhecer-te a ti mesmo do Templo de Delfos não era uma máxima tão fácil de seguir quanto o julgara nas minhas Confissões" (ROUSSEAU, 1959b, p. 1024; trad. bras. 1995 , p. 55).

A ideia de consciência de si nos remete ao papel fundamental da memória na construção do sentimento de existência, cuja compreensão é importante para o estudo da autobiografia que incorpora aspectos das lembranças do nosso autor-personagem na elaboração do seu texto literário. Nesse caso, não mais a experiência direta, mas essa mesma experiência mediada pelas mãos da memória que a escreve, constituindo, portanto, uma experiência estética:

Escrevi minhas Confissões já velho e entediado com os vãos prazeres da vida [...]. Escrevi-os de memória; essa memória me falhava muitas vezes ou somente me fornecia lembranças imperfeitas e eu preenchia suas lacunas com detalhes que imaginava, como complemento dessas lembranças, mas que nunca lhe eram contrárias. [...] Dizia coisas que esquecera, como me parecia que deviam ter sido, como talvez realmente tivessem sido, nunca o contrário do que lembrava terem sido. Algumas vezes, conferia à verdade encantos estranhos, mas nunca a substituí pela mentira para paliar meus vícios ou para me atribuir virtudes (ROUSSEAU, 1959b, p. 1035-1036; trad. bras. 1995, p. 64).

Segundo Burgelin, em Rousseau a memória unifica o sentimento de existência, conferindo individualidade ao ser:

Existência individual e unidade estão assim indissoluvelmente ligadas. Eu sou [alguém único, singular] deve se traduzir imediatamente por: Eu sou uno. A unicidade é ao mesmo tempo unidade [...]. Consciência de si é consciência de uma organização, não unicamente de um ser físico, mas de um ser psíquico: a memória estende o sentimento de identidade sobre todos os momentos de sua existência, tornando-o [esse sentimento] verdadeiramente uno (BURGELIN, 1978, p. 126, grifos do autor).

Dessa maneira, observamos que, se por um lado, a recorrência à memória provoca a reflexão que pode causar a infelicidade e a dor, por outro, a memória organiza as lembranças do indivíduo de tal modo que ele possa dizer "Esta foi/é a minha vida" diferente de todas as outras. Daí advém seu caráter de unidade e unicidade. $\mathrm{O}$ auxílio à memória é igualmente um traço da melancolia de Rousseau que o leva a buscar num tempo perdido sua própria salvação, e isso

\begin{tabular}{|c|c|c|c|c|}
\hline Revista Dialectus & Ano 8 & n. 15 & Agosto - Dezembro 2019 & p. $122-142$ \\
\hline
\end{tabular}


através dos êxtases de um devaneio regulado que, além de conferir unidade e sentido à sua existência, reconstrói as lembranças conforme a força e as intenções da moral do seu sentimento ${ }^{10}$ :

A única verdadeira ruptura em nós é a de nossos erros. Todas as outras desaparecem na unidade da lembrança que restaura a existência. Êxtase e lembrança são dois caminhos de nossa saúde (BURGELIN, 1978, p. 147-148).

Diante disso, podemos afirmar que o "recuo da memória" de algum modo liberta, redime a existência de Rousseau:

[...] minha existência está toda em minha memória, não vivo senão de minha vida passada [...]. Nesse estado, é natural que me agrade voltar os olhos para o passado do qual retiro doravante todo o meu ser; é então que meus erros se corrigem e que o bem e o mal se apresentam a mim sem mistura e sem preconceitos (ROUSSEAU, 1969b, p. 1103, trad. nossa).

Embora alguns conceitos rousseaunianos possam revelar colorações metafísicas, a 135 exemplo das próprias noções de natureza e de existência, o filósofo, costumeiramente, foge desse terreno. Tal fuga certamente se relaciona à posição "marginal" ambicionada por ele em relação aos pensadores da época e à parte de uma tradição filosófica que considerava a filosofia atividade eminentemente intelectual, levando-o à crítica a uma filosofia que, segundo o próprio, era insuficiente para levar a alma e a razão das pessoas a sentirem e agirem conforme a natureza, o que se revela perfeitamente coerente com sua defesa de uma filosofia como forma de vida. No caso da existência, observamos que o genebrino não intenta discutir o ser, a existência sob uma perspectiva ontológica justamente para se descolar da metafísica tanto quanto possível e desejável por ele. Daí advém igualmente o relevo conferido ao sentimento de existência e à "consciência da existência como valor [...] transforma[da] no princípio d[a] [...] vida moral" (BURGELIN,1978, p. 126), ou seja, a existência particular apreendida como

10 O caminho teórico encontrado por Rousseau para afirmar a sinceridade da sua linguagem é considerar a moral do sentimento que se afasta da fixidez do conceito de verdade preconizado pela filosofia moral, o qual corresponderia a uma "verdade que interessa à justiça" (DAMIÃO, 2006, p. 93). É válido apresentar esta distinção a fim de compreendermos, neste contexto, a diferença entre a verdade da justiça e verdade do sentimento. A assunção da moral do sentimento admite o "nomadismo da verdade" (PRADO JR., 2008, p. 371) no qual "a concepção de verdade como função reguladora" (PRADO JR., 2008, p. 372) se torna doravante circunstancial, localizada, efêmera. Rousseau, portanto, assume este nomadismo, no qual a verdade se deslocaria também conforme o sentimento do genebrino, no sentido de preconizar a força da linguagem (no caso, sua opção "velada" pela retórica) para valorar o sentimento autêntico em vez de se ater à veracidade de um fato. Para a autobiografia rousseauniana, importa mais "a autenticidade do relato e não sua fidelidade" (DAMIÃO, 2006, p. 35).

\begin{tabular}{|c|c|c|c|c|}
\hline Rovista Dialectus & Ano 8 & n. 15 & Agosto - Dezembro 2019 & p. $122-142$ \\
\hline
\end{tabular}


critério para avaliar todas as coisas, e também fundamento para o filosofar. Desse modo, o conceito de existência em Rousseau só adquire a devida relevância se entendido na concretude de um sentimento de existir no contexto da condição humana de um estar no mundo que vivencia e indaga a própria existência. Burgelin define sua compreensão do sentimento de existência rousseauniano:

A existência é, portanto, propriamente, consciência de existir, existência por si. Ela é também experiência vivida, ou seja, vinculação ao puro sentimento que se poderia conceber anônimo e como flutuante em qualquer duração informe num centro pronominal [eu] e num enriquecimento progressivo devido ao fato de que se trata sempre de uma presença no mundo que assume a forma pessoal (BURGELIN, 1978, p. 125).

Neste excerto, o filósofo equivale existência à consciência de existir. Tal equivalência trata a "existência por si" como consciência de existir somada à existência enquanto verdade factual (presença no mundo). Em Emílio, Rousseau (1969a, p. 253; trad. bras. 2004, p. 16) nos oferece uma definição mais categórica ao nos informar que o sentimento de existência transcende o estar no mundo: "Viver não é respirar, mas agir; é fazer uso de nossos órgãos, de nossos sentidos, de nossas faculdades, de todas as partes de nós mesmos que nos dão o sentimento de nossa existência”. Burgelin (1978, p. 125) explica que o sentimento de existência é inicialmente "uma presença no mundo antes de ser presença de si”. Entretanto, ele igualmente defenderá que "[...] a consciência de existir é reflexiva e não imediata", pois o pensamento se volta sobre si mesmo para refletir acerca da existência desse "eu", o que nos faz duvidar de um sentimento de existência que surja no indivíduo tão espontaneamente sem a necessidade de pensar. Em face disso, podemos concluir que a existência - quando pensada de modo acontecimental, definida como fenômeno irrepetível na ocasião do surgimento de cada pessoa e tomado o fato de uma existência singular — é imediata, mas o sentimento de existência não o é, já que este, para Burgelin, equivale à consciência de existir, a qual, abrangendo razão e sentimento, significa intenção e atitude que encontram na linguagem (por natureza mediada) sua possibilidade mais recorrente de expressão.

O sentimento de existir instaura nossa existência no sentido de que dele emerge a consciência de si:

Quem não tem plena lucidez do sentimento de existir [...] jamais contemplou [...] sua própria presença no mundo. Não uma presença anônima, mas justamente a minha neste exato momento. Toda a existência humana na sua realidade repousa então, em última análise, sobre a precisão da consciência de si (BURGELIN, 1978, p. 135).

\begin{tabular}{|c|c|c|c|c|}
\hline Qovista Dialectus & Ano 8 & n. 15 & Agosto - Dezembro 2019 & p. $122-142$ \\
\hline
\end{tabular}


A dimensão literária de parte da obra de Rousseau comporta uma filosofia fundada sobre a subjetividade, ou seja, “[...] é um perpétuo retorno à experiência interminável do 'Eu existo"”. Interminável porque essa experiência é incessante ao longo da existência do filósofo devido ao caráter obsessivo e necessário da análise interminável que Rousseau faz de si mesmo, produto da intensificação da consciência de si cuja intensificação, em Rousseau, necessita da solidão para exaltar o sentimento de existência (BURGELIN, 1978, p. 125).

\section{Sentimento de existência: elemento norteador das relações entre a ordem (natureza) e o existir}

Bento Prado Jr. sumariza o conceito de sentimento de existência elaborado por Burgelin (1978) em La Philosophie de l'existence de Jean-Jacques Rousseau, conectando-o à ideia de felicidade e de natureza enquanto perfeição ou ordem:

$\mathrm{Na}$ expressão sentimento de existência, [...] ela não indica a maneira pela qual a existência ou a realidade se reflete no interior da subjetividade, como poderia supor uma leitura "psicologista"; é realmente a própria existência e, com ela, o ser que é desvendado por e nesse sentimento. Visão em Deus? De todo modo, "único modo de adesão ao ser". Pode-se falar de uma experiência direta do ser - e não apenas de um "choque" com a realidade ou de uma experiência bruta - , pois este sentimento que se dá no modo da felicidade o apreende [o ser] como valor; no sentimento da existência, a natureza se mostra como perfectio ou como ordo (PRADO JR., 2008, p. 48, grifos do autor).

No capítulo “L'Existence”, Burgelin (1978, p. 48) considera o sentimento de existência o "único modo de adesão ao ser". Ademais, a ênfase na ideia de felicidade e sua relação com a existência apresenta indícios da relação intrínseca entre a felicidade e o sentimento de existência. Finalmente, ele esclarecerá nesta seção que a felicidade corresponde à plenitude do sentimento de existência. Assim, o que é desvendado por e nesse sentimento é a descoberta de si, a consciência de si, que é igualmente consciência do outro (do mundo exterior em geral) como já explicitado sobre esses opostos complementares. E no bojo dessas descobertas, o indivíduo também descobre a ordem da natureza ou deus conforme a múltipla compreensão de natureza em Rousseau ${ }^{11}$. Desse modo, na abertura para uma adesão ao ser

11 Para compreender o conceito de natureza na obra do filósofo cf. em ROUSSEAU (2004) os livros I e IV; WALLON, Henri. Écrits et souvenirs: Introduction à l'Émile. In: Enfance. Paris, Tome 21, n $1-2$, pp. 53-89, 1968. Disponível em: https://www.persee.fr/doc/enfan_0013-7545_1968_num_21_1_2449 e PAIVA, Wilson A. de. Natureza e natureza: dois conceitos complementares em Rousseau. In: Controvérsia. São Leopoldo, v.3,

\begin{tabular}{|c|c|c|c|c|}
\hline Rovita Didectus & Ano 8 & n. 15 & Agosto - Dezembro 2019 & p. $122-142$ \\
\hline
\end{tabular}


suscitada somente pelo sentimento de existência, a existência singular (que doravante abrange o si mesmo, o outro e a natureza) é apreendida como valor, passando a ser a medida, critério de avaliação de todas as coisas, sendo também concebida como fundamento para um filosofar que "não surge em absoluto de alguma dúvida metódica, mas da aflição do homem diante da complexidade, do dilaceramento e da infelicidade da vida", pois a filosofia é, antes de tudo, uma forma de vida para Rousseau e não apenas uma atividade reflexiva ou trabalho intelectual (PRADO JR., 2008, p. 49).

Para Prado Jr. (2008), Burgelin aponta um dos grandes problemas filosóficos na obra de Rousseau, o qual trata da conciliação entre ordem e existência:

[...] como unificar a ordem e a existência? Uma me remete à minha modesta posição no todo em que Deus reina e na cidade que a lei rege, a outra me coloca no centro. Uma orienta para uma filosofia da razão, a outra para uma exploração do sentimento. Conciliá-las é a meta: fui feito para ser feliz num mundo ordenado (BURGELIN, 1978, p. 572).

Apesar do seu sentido metafísico, “ordem" também aponta para a sociabilidade

("fui feito para ser feliz num mundo ordenado") ainda que esta última devesse, de acordo com Rousseau, ser regida pelos valores emanados da natureza. De algum modo, o excerto sugere algumas das tensões patentes, opostos complementares na obra rousseauniana, a saber: singular-universal, solidão-multidão, natureza-cultura.

Refletindo sobre algumas importantes sínteses elaboradas por ambos os comentadores na análise de Prado Jr. acerca da interpretação existencialista de Burgelin sobre a obra rousseauniana, observamos que aquele conclui que Burgelin define os limites da reflexão sobre o sentimento de existência. Tais limites trafegam entre os polos da ordem e da existência, expondo tanto a abrangência dessa reflexão e também, por essa razão, sua relevância elege a primazia da existência como questão essencial que confere coesão e sentido à obra de Rousseau. Prado Jr. assegura que Burgelin supõe o sentimento de existência como elemento norteador das relações entre existência e ordem:

No universo que o sentimento instaura, esses dois polos - o universal e o singular estão estreitamente ligados: é na experiência direta de si mesmo que a consciência singular obtém a ideia de ordem universal e de Deus, que é o seu princípio [dessa ordem universal] (PRADO JR., 2008, p. 50).

n.2, pp. 60-65, jul./dez. $2007 . \quad$ Disponível em: http://revistas.unisinos.br/index.php/controversia/article/view/7048. 
Por conseguinte, reiteramos que o sentimento de existência unifica esses extremos. Entretanto, aquele não resolve um problema estabelecido por Rousseau em diversas obras: como ser feliz vivendo conforme as orientações da natureza num mundo cujo desenvolvimento, além de ser inescapavelmente produto do artifício para que ele exista como tal, exige que o indivíduo exista de modo artificial para que tenha, segundo a moral da sociedade, um trânsito facilitado na mesma. Apesar disso, o sentimento de existência previne Rousseau do desencanto niilista pois, mesmo numa condição solitária, conecta-o singularmente a si mesmo e à natureza, bem como concretiza a ordem natural no interior do próprio Jean-Jacques, visto que "esse sentimento já abre a subjetividade para aquilo que a ultrapassa [...] [sendo] em si mesmo [...] uma espécie de "visão em Deus"” (PRADO JR., 2008, p. 48).

No exílio voluntário da solidão, Rousseau (1959b, p. 999; trad. bras. 1995, p. 26) muitas vezes é autorreferente para avaliar a si mesmo, colocando-se como parâmetro para muito do que externamente observa e julga na tentativa de afastar quase tudo que é exterior a si considerado por ele ameaçador em seus momentos de delírio: "De agora em diante, tudo o que é exterior a mim me é estranho". Somado a isso, a tripla descoberta desse eu se encontra na relação da consciência consigo mesma no êxtase da fusão romântica do "eu" com Deus e com o mundo. Prado Jr. (2008, p. 50, grifo do autor) confessa ser "o narcisismo da consciência de si [...] o lugar da manifestação da ordem da natureza”. Nos Diálogos, o próprio Rousseau (1959c, p. 802 ; trad. bras. 2012, p. 110), através do olhar do personagem "O Francês", destaca o narcisismo de Jean-Jacques: "Profundamente indiferente a tudo que não toca sua insignificante pessoa, nunca se anima exceto por seu próprio interesse".

Em vista disso, seria tal narcisismo um pressuposto para a ambientação de um “egoísmo estético" (para utilizar o termo kantiano) necessário para a solidão e para fazer emergir o sentimento de existência? Ainda não o sabemos. Entretanto, até agora compreendemos ser a solidão uma atitude existencial e que, ao se excluir do "mundo da mediação e da maldade" (PRADO JR., 2008, p. 51), a reflexão reconstitui a humanidade do homem natural anterior à mediação e ao mal. A solidão seria igualmente um recurso, condição que possibilitaria o procedimento filosófico necessário para fazer aflorar tal reflexão sobre a gênese e os lugares do mal dos quais partirão os valores para definir o que é ou não natural. Diz Rousseau n'Os Devaneios:

[...] minha inteira renúncia ao mundo e esse gosto vivo pela solidão que não mais me abandonou [...]. A obra que empreendia somente podia ser executada num retiro absoluto; exigia longas e calmas meditações, que o tumulto da sociedade não suporta.

\begin{tabular}{|c|c|c|c|c|}
\hline Govista Dialectus & Ano 8 & n. 15 & Agosto - Dezembro 2019 & p. $122-142$ \\
\hline
\end{tabular}


Isso me forçou, por algum tempo, a uma outra maneira de viver, na qual, depois, me senti tão bem, que, tendo-a interrompido desde então, somente por necessidade [...], retomei-a com muito gosto [...] e, quando [...] os homens me reduziram a viver só, [...] isolando-me para me tornar infeliz, tinham feito mais para a minha felicidade do que o soubera fazer eu mesmo (ROUSSEAU, 1959b, p. 1015; trad. bras. 1995, p. 4445).

Rousseau se vale da solidão tanto numa tentativa de marcar sua "superioridade moral" em relação aos demais, quanto no sentido de estar numa posição marginal, alheia à sociedade, e, por essa razão, sentir-se autorizado a criticar a degeneração daquela. Rousseau se acreditava alguém cujo caráter não se havia degenerado igualmente porque escolheu estar ausente da vida social. A partir de então, ele testemunha e prescreve preleções cujo discurso, nesse caso específico, se coaduna com sua forma solitária de vida. Mas Rousseau escreve e, como quase toda escrita, nutre o desejo de dizer ao outro, ainda que reste somente falar sobre si mesmo. Até que ponto não seria oportuno afirmar que a solidão de Rousseau está "acompanhada"?

Prado Jr. (2008, p. 51) afirma que a "intuição dos valores" naturais, ao ultrapassar os obstáculos presentes na sociedade degenerada, possibilita o conhecimento do princípio e da origem (uma ânsia de Rousseau, além de ser interesse recorrente no século XVIII), o qual "pode também guiar a missão prática e mostrar o caminho da salvação", tentativas empreendidas pela sabedoria de Rousseau de recomendar aos outros melhores formas de existência em termos políticos, pedagógicos e morais, "e outras tantas maneiras de subordinar a anarquia da subjetividade e da existência à calma ordenação da natureza". Por um lado, a redenção do indivíduo comporta os caracteres naturais de uma espontaneidade (em oposição à máscara) e graça do sentimento que impelem o "eu" a amar o bem por virtude seguindo em direção ao natural. Por outro, Burgelin (1978, p. 515-516) aponta que, para reconhecer Deus nessa ordem natural, o indivíduo necessita "reencontr[ar] sua humanidade", o que restaurará sua razão, "[n]ão a arte de argumentar, mas a pura visão dos valores eternos e das situações concretas, a razão iluminada por esta voz [da natureza]" que, apesar de só poder ser ouvida silenciando o mundo à nossa volta, nunca se cala e sempre nos traz de volta a essa ordem que é nossa destinação. Em Rousseau, da natureza emana uma verdade à qual a subjetividade do genebrino deve se subordinar a fim de melhor expressar sua existência singular de um modo autêntico, genuíno, verdadeiro em seu sentimento (PRADO JR., 2008). Por fim, podemos dizer que, apesar das perseguições e dos banimentos que sofreu por parte da sociedade europeia de sua época e que o levaram a tal estado de isolamento, a solidão é também um recurso para a

\begin{tabular}{|c|c|c|c|c|}
\hline Revista Dialectus & Ano 8 & n. 15 & Agosto - Dezembro 2019 & p. $122-142$ \\
\hline
\end{tabular}


fabricação do "eu" tanto na vida quanto na obra rousseauniana. Nos Devaneios, assim como nas Confissões e em outros textos autobiográficos, a solidão é um meio para o indivíduo empreender o exame estético de consciência com o intuito de melhor compreender a si mesmo:

\begin{abstract}
Tal sentimento [de que não fora feito para viver em sociedade], alimentado desde a minha infância pela educação, e reforçado, durante toda a minha vida, por esse longo encadeamento de infelicidades e de infortúnios que a preencheu, me fez procurar conhecer, em diferentes épocas, a natureza e o destino de meu ser, com maior interesse e cuidado do que jamais encontrei em nenhum outro homem (ROUSSEAU, 1959b, p. 1012; trad. bras. 1995, p. 42).
\end{abstract}

\title{
REFERÊNCIAS :
}

BURGELIN, Pierre. La philosophie de l'existence de Jean-Jacques Rousseau.

Genève: Slatkine Reprints, 1978.

DAMIÃO, Carla Milani. Sobre o declínio da "sinceridade": filosofia e autobiografia de JeanJacques Rousseau a Walter Benjamin. São Paulo: Edições Loyola, 2006.

PRADO JR., Bento. A retórica de Rousseau. São Paulo: Cosac Naify, 2008.

PRESGRAVE, Lia. Perfectibilidade e educação moral no Emílio de Rousseau: uma conexão necessária. Dissertação (Mestrado em Educação) - Programa de Pós-Graduação em Educação, UFS, São Cristóvão, 2015. Disponível em: https://ri.ufs.br/handle/riufs/4751.

RAYMOND, Marcel. Jean-Jacques Rousseau: la quête de soi et la rêverie. Paris: Librairie José Corti, 1962.

ROSSATTI, Gabriel Guedes. "Leur philosophie est pour les autres; il m'en faudroit une pour moi". In: Revista Natureza Humana - Filosofia e Psicanálise. São Paulo, v. 16, n. 1, pp. 96120, 2014. Disponível em: http://revistas.dwwe.com.br/index.php/NH/issue/view/10.

ROUSSEAU, Jean-Jacques. Les Confessions [1813]. In: Oeuvres complètes. Paris: Gallimard, 1959a (Collection Bibliothèque de la Pléiade, Tome I).

Confissões [1813]. Trad. de Rachel de Queiroz e José Benedicto Pinto. São Paulo: EDIPRO, 2008 (Clássicos Edipro).

. Os devaneios do caminhante solitário [1782]. Tradução, introdução e notas de Fúlvia Maria Luiza Moretto. 3. ed. Brasília: Editora Universidade de Brasília, 1995.

Discours sur l'origine et les fondements de l'inégalité parmi les hommes [1755]. In: Oeuvres complètes. Paris: Gallimard, 1964 (Collection Bibliothèque de la Pléiade, Tome III).

Discurso sobre a origem e os fundamentos da desigualdade entre os homens [1755]. Trad. de Lourdes S. Machado. São Paulo: Abril Cultural, 1973 (Coleção Os Pensadores, XXIV).

\begin{tabular}{|c|c|c|c|c|}
\hline Genista Dialectus & Ano 8 & n. 15 & Agosto-Dezembro 2019 & p. $122-142$ \\
\hline
\end{tabular}


. Émile ou de l'éducation [1762]. In: Oeuvres complètes. Paris: Gallimard, 1969a (Collection Bibliothèque de la Pléiade, Tome IV).

. Emílio ou Da educação [1762]. Trad. de Roberto L. Ferreira. 3. ed. São Paulo:

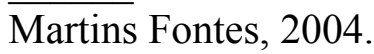

. Lettres morales [1861/1888]. In: Oeuvres complètes. Paris: Gallimard, $1969 \mathrm{~b}$ (Collection Bibliothèque de la Pléiade, Tome IV).

. Les rêveries du promeneur solitarie [1782]. In: Oeuvres complètes. Paris: Gallimard, $1959 \mathrm{~b}$ (Collection Bibliothèque de la Pléiade, Tome I).

. Rousseau, juge de Jean-Jacques: Dialogues [1782]. In: Oeuvres complètes. Paris: Gallimard, 1959c (Collection Bibliothèque de la Pléiade, Tome I).

Rousseau, judge of Jean-Jacques: Dialogues [1782]. Hanover, New Hampshire: Darthmouth College Press, 2012 (The Collected Writings of Rousseau, v. I).

SILVA, Franklin Leopoldo. Prefácio. In: DAMIÃO, Carla Milani. Sobre o declínio da "sinceridade": filosofia e autobiografia de Jean-Jacques Rousseau a Walter Benjamin. São Paulo: Edições Loyola, 2006.

STAROBINSKI, Jean. Jean-Jacques Rousseau: a transparência e o obstáculo. Trad. de Maria Lúcia Machado. São Paulo: Companhia das Letras, 2011.

TAYLOR, Charles. As fontes do self: a construção da identidade moderna. Trad. de Adail Ubirajara Sobral e Dinah de Abreu Azevedo. São Paulo: Edições Loyola, 1997.

\begin{tabular}{|l|l|l|l|l|}
\hline Govista Dialectus & Ano 8 & n. 15 & Agosto-Dezembro 2019 & p. $122-142$ \\
\hline
\end{tabular}

